\title{
A FORMAÇÃO DE PROFESSORES PARA A EDUCAÇÃO INCLUSIVA E OS POSSÍVEIS IMPACTOS NA ESCOLARIZAÇÃO DE ALUNOS COM DEFICIÊNCIAS ${ }^{*}$
}

\author{
Mônica de Carvalho Magalhâes Kassar ${ }^{* *}$
}

\begin{abstract}
RESUMO: A educação brasileira prevê dois tipos de professores para atuar no magistério com alunos com deficiências: os capacitados e os especializados. Este artigo tem o propósito de analisar características da formação de professores, considerando os programas do governo federal para a formação de um sistema educacional inclusivo. Os resultados evidenciam a existência de grande número de professores graduados, em especial os que atuam no atendimento educacional especializado e na educação especial. No entanto, as análises indicam precariedade da formação quando os dados são cotejados, levando-se em conta as características dos programas de formação e o nível de escolarização dos alunos com deficiências.
\end{abstract}

Palavras-chave: Formação de professores. Educação especial. Escolarização de alunos com deficiências. Política educacional.

\footnotetext{
* Uma primeira versão sobre este tema foi apresentado pela autora na mesa "Políticas e práticas de formação de professores: impactos nos anos iniciais da educação básica", durante a $36^{a}$ Reunião Anual da ANPEd, ocorrida em Goiânia, de 29/09 a 02/10 de 2013.

** Departamento de Educação da Universidade Federal do Rio Grande do Sul (UFRGS). Corumbá (MS) - Brasil.

Contato com a autora: <monica.kassar@pq.cnpq.br>
} 
A formação de professores para a educação inclusiva e os possíveis impactos...

TEACHER DEVELOPMENT FOR INCLUSIVE EDUCATION AND THE POSSIBLE IMPACT ON STUDENTS WITH DISABILITIES' SCHOOLING

ABSTRACT: Brazilian education legislation establishes that two kinds of teachers may work with students with disabilities: those who have short-term and long-term training. The aim of this article is to analyse the characteristics of teacher development, considering federal government programs that aim to prepare for an inclusive educational system. The results indicate that there is a large number of teachers with university degrees, mainly those that teach in specialized educational services and in special education. Nevertheless, analyses indicate that teacher development is problematic when data are compared, considering the characteristics of development programs and the schooling level of students with disabilities.

Key words: Teacher development. Special education. Students with disabilities. Educational policies.

\section{Introdução}

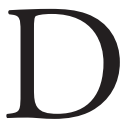

esde a década de 1990, há de forma mais evidente a disseminação de um discurso que garante a todo aluno o direito de ser escolarizado e a frequentar a escola comum. Esse discurso faz-se presente desde a política de universalização das matrículas no ensino fundamental no governo de Fernando Henrique Cardoso. Esse movimento foi favorecido, em grande medida, pela assinatura, por parte do Estado brasileiro, de acordos internacionais para superação do analfabetismo e para a melhoria das condições de educação da população brasileira, que alicerçaram documentos nacionais, cuja meta principal era "assegurar, até o ano de 2000, a crianças, jovens e adultos conteúdos mínimos de aprendizagem” (BRASIL, 1993, p. 13). A partir de então, entre os alunos que devem frequentar a escola, estão aqueles "com necessidades educacionais especiais" e, entre estes, os que possuem alguma deficiência.

Em 2001, a Resolução n. CNE/CEB 02/2001, que define as Diretrizes Nacionais para a Educação Especial na Educação Básica, estabeleceu dois tipos de professores aptos a assumir o magistério para os "alunos com necessidades educacionais especiais", em seu artigo 18: os "capacitados" e os "especializados". Esses docentes têm atribuições diferenciadas. Para receber os alunos em classes comuns, devem ser capacitados; para assumir 
as atividades de atendimento educacional especializado, devem ser especializados, das seguintes formas:

$\$ 1$ o São considerados professores capacitados para atuar em classes comuns com alunos que apresentam necessidades educacionais especiais aqueles que comprovem que, em sua formação, de nível médio ou superior, foram incluídos conteúdos sobre educação especial adequados ao desenvolvimento de competências e valores para:

I - perceber as necessidades educacionais especiais dos alunos e valorizar a educação inclusiva;

II- flexibilizar a ação pedagógica nas diferentes áreas de conhecimento de modo adequado às necessidades especiais de aprendizagem;

III - avaliar continuamente a eficácia do processo educativo para o atendimento de necessidades educacionais especiais;

IV - atuar em equipe, inclusive com professores especializados em educação especial.

$\$ 2^{\circ}$ São considerados professores especializados em educação especial aqueles que desenvolveram competências para identificar as necessidades educacionais especiais para definir, implementar, liderar e apoiar a implementação de estratégias de flexibilização, adaptação curricular, procedimentos didáticos pedagógicos e práticas alternativas, adequadas aos atendimentos das mesmas, bem como trabalhar em equipe, assistindo o professor de classe comum nas práticas que são necessárias para promover a inclusão dos alunos com necessidades educacionais especiais.

$\$ 3^{\circ}$ Os professores especializados em educação especial deverão comprovar:

I - formação em cursos de licenciatura em educação especial ou em uma de suas áreas, preferencialmente de modo concomitante e associado à licenciatura para a educação infantil ou para os anos iniciais do ensino fundamental;

II - complementação de estudos ou pós-graduação em áreas específicas da educação especial, posterior à licenciatura nas diferentes áreas de conhecimento, para atuação nos anos finais do ensino fundamental e no ensino médio.

$\$ 4^{\circ}$ Aos professores que já estão exercendo o magistério devem ser oferecidas oportunidades de formação continuada, inclusive em nível de especialização, pelas instâncias educacionais da União, dos estados, do Distrito Federal e dos municípios. (BRASIL, 2001) 
A formação de professores para a educação inclusiva e os possíveis impactos...

Tais proposições, cremos, deveriam ter tido impacto imediato nos estudos a respeito da formação inicial de professores para a educação básica, uma vez que induzem tais cursos a incluir, em seus currículos, "conteúdos sobre educação especial”. No entanto, ao fazer um levantamento dos trabalhos publicados nos Anais da Associação Nacional de Pós-Graduação e Pesquisa em Educação (ANPEd), entre os anos de 2001 a 2007, verificamos que, ao menos no âmbito da academia, a discussão sobre a formação do professor que considerasse as especificidades de alunos com deficiências permaneceu restrita ao grupo de trabalho da Educação Especial (GT 15), sendo raros os artigos do grupo de trabalho de formação de professores a abordar a temática.

A partir de 2003, no Governo Lula, evidenciaram-se mais enfaticamente alterações para a proposta de atendimento escolar ao aluno foco da educação especial. Desde o primeiro ano do primeiro mandato, foram lançados programas objetivando um modelo de atendimento formalizado a partir de 2007, com o Programa de Implantação de Salas de Recursos Multifuncionais. Tal modelo pode ser simplificado na seguinte expressão: Matrículas em salas comuns + Apoio de atendimento educacional especializado em sala de recursos multifuncionais = Atendimento educacional adequado para alunos foco da Educação Especial, ou seja, ao aluno com deficiência deveria ser garantida a matrícula nas salas de aula comuns das escolas públicas e sua escolaridade complementada (ou suplementada, no caso de alunos com altas habilidades), preferencialmente em salas de recursos multifuncionais. Essa estrutura passou a ser entendida como atendimento educacional especializado por excelência, adequada a compor um sistema educacional inclusivo.

O Programa de Implantação de Salas de Recursos Multifuncionais faz parte do conjunto de ações que sustentam a política educacional denominada de "Educação Inclusiva" ou do modelo de educação inclusiva assumido pelo governo federal desde a primeira gestão do Governo Lula, que tem como meta formar sistemas educacionais inclusivos. O Programa dissemina a instalação das salas de recursos multifuncionais nas instituições de ensino e fornece infraestrutura para sua montagem. Segundo o Ministério da Educação, de 2005 a 2013, foi iniciada a implantação de 39.301 salas, distribuídas em 5.046 municípios do país.

Lembrando que são mantidas as Diretrizes Nacionais para a Educação Especial na Educação Básica, com suas exigências na formação de professores, 
a ênfase nessa estrutura de atendimento favorece certo "desconforto"/ desafio sobre/para a formação inicial do professor da educação básica (o "capacitado") e uma "reconfiguração" na formação do professor "especializado".

A partir do quadro ora descrito, o objetivo deste artigo é analisar algumas características da formação de professores, considerando os programas recentes do governo federal para a formação de um sistema educacional inclusivo.

\section{Um novo professor?}

Junto ao Programa de Implantação de Salas de Recursos, há um elenco de outros programas e projetos com intuito de materializar essa política educacional. Muitos se referem à formação de professores (inicial ou em serviço) $)^{2}$ :

- Educação Inclusiva: Direito à Diversidade, que visa à formação de educadores e gestores, por sistema de multiplicadores, para disseminar a proposta de educação inclusiva e transformar os sistemas de ensino atuais em sistemas de ensino inclusivos. Foram formados 80 mil professores. Segundo o Ministério da Educação, alcançou $100 \%$ do território nacional. Na gestão de Dilma Rousseff este programa passou a ser oferecido pela Secretaria de Educação Continuada, Alfabetização, Diversidade e Inclusão (Secadi);

- Formação de Professores para o Atendimento Educacional Especializado, que atendeu a formação continuada de professores, prioritariamente na modalidade a distância;

- Formação para Atuação nas Salas de Recursos;

- Programa Interiorizando Braille, com a formação de 1.500 professores;

- Programa Interiorizando Libras, com a formação continuada de 1.890 professores;

- Programa Nacional de Formação Continuada de Professores na Educação Especial - modalidade a distância, que ofereceu 70 mil vagas;

- Projeto de Informática na Educação Especial (Proinesp): curso de formação de 2.350 professores; 
A formação de professores para a educação inclusiva e os possíveis impactos...

- Projeto Educar na Diversidade, em que foram formados 33 mil professores;

Atualmente, a página online do Ministério da Educação exibe o Programa de formação continuada de professores em educação especial, que apresenta como objetivo "apoiar a formação continuada de professores para atuar nas salas de recursos multifuncionais e em classes comuns do ensino regular, em parceria com Instituições Públicas de Educação Superior”. ${ }^{3}$ O Programa deve oferecer cursos de aperfeiçoamento e especialização nas modalidades a distância, presencial e semipresencial, por meio da Universidade Aberta do Brasil (UAB) e pela Rede Nacional de Formação Continuada de Professores na Educação Básica (Renafor).

É grande o número de ações para formação continuada de professores, fato que possibilita a dedução de que, para o governo federal, este aspecto é crucial para a implantação da política educacional adotada. Se a formação do professor é um aspecto fundamental, em que consistiria a peculiaridade dessa formação? Quais suas características? Garcia (2013) entende que o foco da política educacional inclusiva é o Programa de Implantação de Salas de Recursos Multifuncionais e, sendo assim, adverte que

[...] há uma preocupação em formar um novo professor de educação especial, reconvertido, que não vai atuar nas instituiçōes especializadas, classes especiais ou salas de recursos de atendimento por área de deficiência. Trata-se de formar em serviço o professor do AEE [atendimento educacional especializado] realizado na SEM [sala de recursos multifuncional]. Tal serviço pode atender a todos os alunos considerados oficialmente como público-alvo da educação especial. (GARCIA, 2013, p. 213)

Das análises de Garcia (op. cit.), podemos ressaltar ao menos dois aspectos que nos parecem conflitantes. O primeiro consiste na característica da atuação do professor: uma sala de recursos multifuncionais requer um professor também multifuncional, que seja capaz de atuar em diferentes frentes, para atender diferentes deficiências. Sua formação não deve, portanto, ser restrita, mas generalista. O outro aspecto refere-se ao público-alvo da educação especial. Desde a aprovação da Lei de Diretrizes e Bases da Educação Nacional, em 1996, o atendimento educacional especializado passou a ser direcionado aos "educandos com necessidades educacionais especiais”, conceito definido em 2001 pelas Diretrizes Nacionais para a 
Educação Básica na Educação Especial, em seu Artigo 5º, como aqueles alunos que, durante o processo educacional, apresentam:

I - dificuldades acentuadas de aprendizagem ou limitaçóes no processo de desenvolvimento que dificultem o acompanhamento das atividades curriculares, compreendidas em dois grupos:

a) aquelas não vinculadas a uma causa orgânica específica;

b) aquelas relacionadas a condições, disfunções, limitações ou deficiências;

II - dificuldades de comunicação e sinalização diferenciadas dos demais alunos, demandando a utilização de linguagens e códigos aplicáveis;

III - altas habilidades/superdotação, grande facilidade de aprendizagem que os leve a dominar rapidamente conceitos, procedimentos e atitudes. (BRASIL, 2001)

Logo após o lançamento do Programa de Implantação de Sala de Recursos Multifuncionais, a Política Nacional de Educação Especial na perspectiva da educação inclusiva foi apresentada em 2008, definindo como foco das ações da educação especial os alunos com deficiência, transtornos globais de desenvolvimento e altas habilidades/superdotação. Assim, o docente multifuncional a ser formado também deve receber/possuir conhecimentos específicos para escolarizar os alunos ora referenciados, o que significa certa especificidade. Pensando no desafio da capacitação de professores, tanto os capacitados quanto os especialistas, uma mesma questão se apresenta: Qual tem sido essa formação?

\section{A formação dos professores que estão atuando em nossas escolas}

Com a intenção de responder a questão anteriormente colocada, recorremos aos dados do Censo Escolar do ano de 2012 para conhecer as características gerais da formação de professores que atuam na educação básica das escolas públicas brasileiras. Para o propósito deste texto, consideramos docentes atuantes na educação infantil, ensino fundamental de nove anos e ensino médio de três anos, das redes municipal, estadual e federal, das cinco regióes do país.

A Tabela 1 apresenta a formação dos docentes no ensino superior que atuam na educação básica e a porcentagem dos que possuem como formação máxima, especialização, mestrado ou doutorado. Verifica-se, 
A formação de professores para a educação inclusiva e os possíveis impactos...

nos dados expostos, que uma grande parcela dos docentes possui curso superior (graduação), sendo $77 \%$ dos docentes atuantes nessa etapa de ensino do país. A região que concentra menor percentagem de docentes com essa formação é o Nordeste $(67 \%)$ e a Centro-Oeste é a região com maior percentagem (83\%). Já em relação à formação em cursos de especialização e mestrado, a região Sul é a que concentra a maior porcentagem desses profissionais; a Sudeste apresenta a maior concentração de doutores atuando do ensino básico. Os dados indicam, portanto, que a grande maioria dos professores do ensino básico no país possui o ensino superior completo. A partir desta constatação, cabe perguntar: Onde os docentes estão se formando?

\section{Tabela 1}

Formação do docente da educação básica* do ensino público, em ensino superior (ES): 2012

\begin{tabular}{l|c|c|c|c|c|c}
\hline & $\begin{array}{c}\text { Docentes } \\
\text {-Geral } \\
\text { TOTAL* }\end{array}$ & $\begin{array}{c}\text { Docentes } \\
\text { com ES }\end{array}$ & $\begin{array}{c}\text { Docentes } \\
\text { com ES\% }\end{array}$ & $\begin{array}{c}\text { ES com } \\
\text { Especialização } \\
\%\end{array}$ & $\begin{array}{c}\text { ES } \\
\text { Mestrado } \\
\%\end{array}$ & $\begin{array}{c}\text { ES } \\
\text { Doutorado } \\
\%\end{array}$ \\
\hline Brasil & 1.308 .476 & 1.003 .253 & 77 & 36,5 & 1 & 0,1 \\
Centro-Oeste & 105.952 & 88.277 & $\mathbf{8 3}$ & 39,6 & 0,99 & 0,09 \\
Sudeste & 525.896 & 424.237 & $\mathbf{8 1}$ & 33 & 1,3 & 0,18 \\
Nordeste & 348.915 & 232.464 & $\mathbf{6 7}$ & 32 & 0,88 & 0,08 \\
Norte & 107.668 & 78.898 & $\mathbf{7 3}$ & 26 & 0,85 & 0,12 \\
Sul & 222.045 & 179.377 & $\mathbf{8 1}$ & 54 & 1,78 & 0,14 \\
\hline
\end{tabular}

* Considerados docentes em educação infantil (creche e pré-escola), ensino fundamental de nove anos e ensino médio de três anos.

Fonte: Microdados do Inep tabulados por Rafael Verão Françozo. Organização da autora.

Quando verificamos o local de formação dos professores, se em instituição pública ou privada, identificamos algumas diferenças entre as regiōes do país. Sudeste e Sul têm grande porcentagem de professores formados em instituições particulares. Ressalta-se que, nestas regiōes, encontra-se o maior número de universidades públicas do país. Essas 
informações levam a crer que, nas regiōes do país em que as instituições públicas poderiam responder pela formação dos docentes, sua presença é restrita (Sul: 34\% e Sudeste: 21\%).

\section{Tabela 2}

Formação em ensino superior (ES) de professores da educação básica brasileira*: relação entre Instituições do Ensino Superior (IES) públicas e privadas: 2012 - \%

\begin{tabular}{|l|l|l|l|}
\hline & \multicolumn{3}{|c|}{ Professores totais } \\
\cline { 2 - 4 } & ES & IES pública & IES privada \\
\hline Brasil & 77 & 42 & 58 \\
CO & 83 & 57 & 43 \\
SE & 81 & 21 & 79 \\
NE & 67 & 70 & 30 \\
N & 73 & 73 & 27 \\
S & 81 & 34 & 66 \\
\hline
\end{tabular}

* Considerados docentes em educação infantil (creche e pré-escola), ensino fundamental de nove anos e ensino médio de três anos. Fonte: Microdados do Inep tabulados por Rafael Verão Françozo. Organização da autora.

Por outro lado, observa-se grande número de docentes graduados em instituições de ensino superior públicas no Norte (73\%) e Nordeste (70\%). Consideramos importante cotejar esses dados com os do Plano Nacional de Formação de Professores da Educação Básica (Parfor) em 2012. Nesse ano, $50,3 \%$ dos docentes graduados no programa eram do Norte (28.073 graduados) e $37,1 \%$ do Nordeste (20.722 graduados). Ainda, se acrescentarmos a informação de que, pela Universidade Aberta do Brasil (UAB), em $2012,56,99 \%$ das formações foram graduações em licenciaturas e 20,81\% foram especializações (considerando-se as matrículas em todo o país), há uma grande possibilidade de que um alto índice dos docentes do ensino básico formou-se em instituições públicas, nas modalidades a distância ou semipresencial. Entre esses docentes, estão os que são tidos como capacitados, ou seja, os que foram formados para atuar no ensino comum e que devem possuir em seus currículos conteúdos de educação especial.

A seguir, apresentamos o quadro referente à formação dos docentes que devem ser considerados especializados, já que atuam diretamente em 
A formação de professores para a educação inclusiva e os possíveis impactos...

atendimento de educação especial (EE) - classes ou escolas especiais, na forma substitutiva à escolaridade comum - e em atendimento educacional especializado (AEE) - em especial, nas salas de recursos multifuncionais.

\section{Tabela 3}

Formação em ensino superior de professores da educação básica brasileira* atuantes na EE e em AEE. Relação entre IES públicas e privadas: 2012 - \%

\begin{tabular}{|l|c|c|c|c|c|c|}
\hline \multirow{2}{*}{} & \multicolumn{3}{|c|}{ Professores em EE } & \multicolumn{3}{c|}{ Professores em AEE } \\
\cline { 2 - 7 } Brasil & ES & Pub. & Priv. & ES & Pub. & Priv. \\
CO & 85 & 36 & 64 & 88 & 43 & 57 \\
SE & 97 & 29 & 72 & 96 & 50 & 50 \\
NE & 80 & 25 & 75 & 90 & 19 & 81 \\
N & 70 & 58 & 42 & 80 & 68 & 32 \\
S & 89 & 72 & 28 & 83 & 69 & 31 \\
\hline
\end{tabular}

* Considerados docentes em educação infantil (creche e pré-escola), ensino fundamental de nove anos e ensino médio de três anos. As colunas 1 e 4 indicam a porcentagem de docentes com ES completo que atuam como especializados em cada região. As colunas 2, 3,5 e 6 foram calculadas a partir da totalidade de docentes com ES atuante em cada região e em cada forma de atendimento (EE ou AEE).

Fonte: Microdados do Inep tabulados por Rafael Verão Françozo. Organização da autora.

Quando se exibem os dados de formação dos docentes que atuam como especializados, cresce a porcentagem de graduados em todas as regiões, à exceção dos professores que atuam na educação especial (modalidade substitutiva) na região Sudeste. Vemos também, entre esses docentes, a forte presença do ensino superior privado (mais uma vez, em menos peso nas regióes Norte e Nordeste).

De certo modo, tais dados indicam que grande parte dos docentes que atuam tanto como capacitados quanto especialistas forma-se em instituições privadas ou nas modalidades a distância ou semipresencial de instituições públicas. Este aspecto merece atenção. Bueno (2002), em levantamento realizado com dados do Ministério da Educação de 1998, registrou naquele momento 23 universidades que ofereciam graduação em educação especial. Em 2013, apesar do crescente número de matrículas de crianças - foco da 
educação especial - nas escolas da educação básica, apenas sete instituições (duas públicas - uma no Sul e outra do Sudeste - e cinco não públicas no Sul) oferecem 19 cursos. Este aspecto evidencia algumas contradições: 1) nos últimos 20 anos, o número de cursos de graduação direcionados à formação de especialistas em EE parece diminuir, quando há uma demanda crescente de formação de docentes; 2) apesar da grande porcentagem de graduados com formação para atuar como especializados, ou seja, que atuam na educação especial substitutiva no Nordeste $(70 \%)$ e no Norte $(89 \%)$ ou no Atendimento Educacional Especializado (80\% no Nordeste e 83\% no Norte), não há registro de nenhum curso de graduação em educação especial nessas regiōes. Essa situação reforça a suposição de que a formação desses docentes pode ter ocorrido na modalidade a distância e pode explicar a grande procura por cursos oferecidos pela UAB nessas regiōes. Acrescenta-se que, nos programas do governo federal de formação à docência, há o fomento de oferta de turmas especiais em cursos de licenciatura ou segunda licenciatura para docentes ou tradutores/intérpretes de Libras em exercício na rede pública da educação básica; formação pedagógica para docentes ou tradutores/intérpretes de Libras graduados não licenciados que se encontram no exercício da docência na rede pública da educação básica. ${ }^{4}$ Registra-se, também, o grande número de matrículas de docentes no sistema UAB. Em dezembro de 2012, eram 249.665 matrículas distribuídas em 635 municípios polos. 5

Outra hipótese é que a formação vista como especializada tem sido obtida nos cursos de capacitação em serviço dos programas no governo federal, como Educação Inclusiva: Direito à Diversidade, Programa Nacional de Formação Continuada de Professores na Educação Especial ou, ainda, Interiorizando Braille ou Interiorizando Libras. Cabe acrescentar, aqui, as características dos programas de formação continuada sobre a educação inclusiva, utilizando como exemplo o Programa Educação Inclusiva: Direito à Diversidade que, há dez anos em implantação, já atingiu todos os municípios brasileiros, com cursos de 20 horas anuais (concentradas em uma semana), na forma de ação de multiplicadores. Com essa estrutura, tais programas conseguem registrar um grande número de docentes ou gestores formados (mais de 80 mil até 2012). Percebe-se, ainda, que os programas que atendem a um maior número de professores contemplam temáticas mais gerais. Já os projetos de formação específica (como Libras e Braille) registram público mais restrito. 
A formação de professores para a educação inclusiva e os possíveis impactos...

Pela descrição exposta dos cursos de formação em serviço, é possível reforçar a hipótese de que a capacitação de docentes para receber os alunos com deficiências, transtornos globais do desenvolvimento e os superdotados ou com altas habilidades, tanto para as classes comuns quanto para aqueles que atuam no atendimento especializado (capacitados ou especializados), tem - de modo geral - as seguintes características: ocorre em instituições privadas ou é oferecida por instituições públicas, mas de modo não presencial ou por multiplicadores.

\section{A formação no campo da educação especial}

O campo da educação especial posiciona-se, atualmente, diante de alguns desafios no que concerne à formação de docentes. Jesus, Barreto e Gonçalves (2011) desenvolveram uma meta-análise dos trabalhos no GT 15 sobre formação de professores entre os anos de 2000 e 2010. As autoras identificaram ambiguidades levantadas em diferentes trabalhos sobre a formação do docente. Dentre os trabalhos analisados, ressaltamos o de Possa e Naujorks (2009 apud JESUS; BARRETO; GONÇALVES, 2011) que, a partir do estudo de diferentes produções, identificaram uma preocupação com a formação de docentes para atuar em uma educação inclusiva. Quanto à formação inicial, as autoras concluíram que há "[...] a ideia de que se o professor aprender na formação alguns ajustes à realidade existente, será possível corrigir e adaptar este sujeito à escola" (POSSA; NAUJORKS, 2009 apud JESUS; BARRETO; GONÇALVES, 2011, p. 81).

Em relação às pesquisas sobre a formação continuada, parte considerável dos trabalhos tem apontado precariedades e limitações nos cursos de formação direcionados à educação especial, favorecidos pelos programas do governo federal (JESUS; BARRETO; GONÇALVES, 2011). Essa constatação reforça nossa percepção sobre tais cursos.

A leitura de diferentes trabalhos com a temática "formação de professores" para a educação especial ou a educação inclusiva propicia a formulação de questóes para nosso campo de pesquisa: Que tipo de conhecimento é relevante para uma formação do professor da educação básica, levando-se em conta a escolarização dos alunos com deficiências? Que tipo de conhecimento é necessário para formar o professor considerado "especialista"?

Percebemos que não há consenso dentro do próprio campo. Enquanto autores entendem que a educação especial comporta um conjunto 
de conhecimentos historicamente constituídos que deve ser considerado na formação de professores, outros acreditam que a educação especial - em si - já se caracteriza como fonte/forma de segregação de alunos. A pergunta lançada por Costa (2005, p. 67) é exemplar dessa perspectiva:

[...] não é o momento de pensar a própria concepção de educação especial, uma vez que ela contém a ideia de discriminação, de segregação, de barbárie, de exclusão escolar, social e cultural dos educandos com deficiência denominada "especial", ou seja, inadaptados, desiguais?

\section{Possíveis impactos?}

Como mais um elemento para a investigação a respeito da formação de docentes da educação básica, julgamos ser interessante acrescentar dados de matrículas de alunos com deficiências, transtornos globais do desenvolvimento e superdotação/altas habilidades entre os anos de 2007 e 2012. Para possibilitar as análises, escolhemos dados de um município do interior do país, que é polo do Programa Educação Inclusiva: Direto à Diversidade, do governo federal, e que tem adotado integralmente os projetos e propostas do governo central, ou seja, é foco das ações implantadas pelos diferentes programas.

Pela Tabela 4, constata-se que, apesar de retrações em 2008 e 2009, o município apresenta tendência de crescimento de matrículas de alunos com deficiências, transtornos globais do desenvolvimento e superdotação/ altas habilidades. Esse crescimento também é registrado na totalidade do país. Outro aspecto evidente é a persistência de grande concentração de matrículas no $2^{\circ}$ ano (antiga $1^{\mathrm{a}}$ série), indicando que há pouco avanço na escolaridade desses alunos. Pelo acesso aos dados de um município de médio porte, foi possível verificar ainda alguns aspectos interessantes: 1) à exceção da pré-escola, não há nenhum aluno com deficiência na série adequada à sua idade; 2) acompanhando série a série os alunos, verificou-se que, mesmo quando há o número idêntico de matrículas em anos seguintes (por exemplo: 4 alunos no $1^{\circ}$ ano do ensino médio em 2010,4 alunos no $2^{\circ}$ ano do ensino médio em 2011 e 4 alunos no $3^{\circ}$ ano do ensino médio em 2012), não são os mesmos alunos que avançaram, ou seja, não houve aprovação; 3 ) as idades dos alunos são muito altas (por exemplo, encontramos alunos com 20 anos no $3^{\circ}$ ou $4^{\circ}$ ano do ensino fundamental). 
A formação de professores para a educação inclusiva e os possíveis impactos...

\section{Tabela 4}

Total de matrículas de estudantes com alguma deficiência no ensino comum* no município de Corumbá (MS) por série no período de 2007-2012

\begin{tabular}{|c|c|c|c|c|c|c|}
\hline Série & 2007 & 2008 & 2009 & 2010 & 2011 & 2012 \\
\hline Creche & 0 & 1 & 0 & 1 & 1 & 2 \\
\hline Pré-escola & 3 & 5 & 2 & 6 & 5 & 4 \\
\hline $\mathrm{EF} 1^{\circ}$ ano & 15 & 4 & 3 & 12 & 8 & 10 \\
\hline $\mathrm{EF} 2^{\circ}$ ano & 26 & 30 & 31 & 47 & 59 & 59 \\
\hline $\mathrm{EF} 3^{\circ}$ ano & 25 & 15 & 11 & 20 & 36 & 27 \\
\hline $\mathrm{EF} 4^{\circ}$ ano & 28 & 9 & 14 & 20 & 21 & 29 \\
\hline $\mathrm{EF} 5^{\circ}$ ano & 20 & 11 & 11 & 15 & 19 & 17 \\
\hline $\mathrm{EF} 6^{\circ}$ ano & 9 & 11 & 9 & 12 & 15 & 14 \\
\hline $\mathrm{EF} 7^{\circ}$ ano & 7 & 6 & 8 & 9 & 12 & 13 \\
\hline $\mathrm{EF} 8^{\circ}$ ano & 0 & 10 & 5 & 6 & 5 & 12 \\
\hline EF $9^{\circ}$ ano & 2 & 1 & 5 & 4 & 3 & 4 \\
\hline EM 1 asérie & 2 & 3 & 2 & 4 & 6 & 7 \\
\hline EM 2asérie & 1 & 1 & 2 & 2 & 4 & 4 \\
\hline EM 3asérie & 1 & 1 & 1 & 2 & 1 & 4 \\
\hline Total & 139 & 108 & 104 & 160 & 195 & 206 \\
\hline
\end{tabular}

* Considerados docentes em educação infantil (creche e pré-escola), ensino fundamental de nove anos e ensino médio de três anos.

Fonte: Microdados do Censo Escolar, tabulação e organização de Rafael Verão Françozo.

\section{Algumas considerações}

Uma análise da formação do professor para a escolaridade dos alunos foco da educação especial deve levar em conta diferentes aspectos que transcendem questôes específicas desse campo de estudos, como os impactos da privatização do ensino superior, como verificado fortemente nas regiôes Sudeste e Sul, e uma "massificação" do ensino, através de cursos não presenciais oferecidos pelas universidades públicas (através da UAB) e por instituiçōes privadas, aspectos estes já analisados por diversos autores (BITTAR; STAPANI RUAS, 2012; JEZINE, 2013). 
Em relação à especificidade da educação especial, chama a atenção o fato de que, no mesmo período em que há o aumento da matrícula de alunos com deficiências nas escolas comuns de educação básica, há a diminuição da oferta de cursos específicos presenciais nas universidades públicas. Esse aspecto talvez esteja ligado a uma "crise de identidade" da própria área, pois alguns autores acreditam que, com a educação inclusiva, não haveria mais necessidade da educação especial e o próprio campo teria uma característica de segregação (COSTA, 2005). Dessa forma, a disseminação do discurso de inclusão pode ser utilizada para a desconsideração da necessidade de conhecimentos específicos na formação de professores, reforçando a ideia de que bastariam algumas adaptaçôes e os problemas de escolaridade dos alunos com deficiência estariam resolvidos, como percebido em diferentes trabalhos por Possa e Naujorks (2009).

Esses aspectos sobre a formação de docentes nos remetem a uma análise desenvolvida por Saviani e apresentada na reunião anual da Anped em 2008 (SAVIANI, 2009), em que identifica, na história recente da formação docente, a presença de uma formação mais barata, por meio de cursos de curta duração.

O autor ainda debruça-se sobre a formação de professores, abordando dois modelos de formação: modelo dos conteúdos culturais cognitivos e modelo pedagógico-didático. Nessa análise, chama a atenção para a perspectiva corrente de que a universidade "nunca se preocupou com a formação específica, isto é, com o preparo pedagógico-didático dos professores" (SAVIANI, op. cit., p. 149).

O autor explica que o que ocorre, na verdade, é a presença de dois modelos diferentes de formação, o que favorece um dilema para formação docente: "O dilema se expressa do seguinte modo: admite-se que os dois aspectos - os conteúdos de conhecimento e os procedimentos didático-pedagógicos - devam integrar o processo de formação de professores. Como, porém, articulá-los adequadamente?" (ibid., p. 151). Pensando na formação desses professores e tendo em vista a escolarização de alunos com deficiências, o autor lembra, ainda, que as Diretrizes Curriculares Nacionais para o curso de graduação em Pedagogia mal toca nessa questão.

Diante desses aspectos, vemos que os desafios para a formação docente apresentam-se de diferentes ordens: por um lado, pelas características adotadas pela política de ensino superior do país e pela política de formação docente. Por outro lado, pela "crise de identidade" do próprio campo do 
A formação de professores para a educação inclusiva e os possíveis impactos...

conhecimento, que comporta hoje trabalhos que buscam a especificidade na escolarização dos alunos com deficiências, transtornos globais do desenvolvimento de superdotação/altas habilidades, e outros que entendem não haver uma especificidade na área. Em relação a esses aspectos, Jesus, Barreto e Gonçalves (2011) perguntam se haveria um saber-fazer próprio na área de educação especial, constitutivo da aprendizagem de docência como foco da formação do professor. Assim, para enfrentar o dilema identificado por Saviani, a articulação entre os conteúdos de conhecimento e os procedimentos didático-pedagógicos, há que se superar um dilema dentro do próprio campo de conhecimento.

A partir do levantamento desses aspectos, podemos também perguntar: $\mathrm{O}$ modelo proposto de especializado e capacitado é viável e suficiente? Se sim, quais devem ser as características dessas formaçõos?

Parece-nos que estamos diante de um grande desafio, considerando-se que não há consenso - dentro da própria área - em relação à formação apropriada de professores para escolarizar satisfatoriamente a população historicamente identificada como "da educação especial". Esse consenso parece inexistir tanto para a formação do "capacitado" como para a do "especializado".

Concluindo (momentaneamente), os aspectos da função docente levantados por Saviani parecem esvaziados de sentidos, silenciados/apagados pelo discurso da multifuncionalidade docente ou de uma educação inclusiva, que se sustenta "nos pequenos ajustes" e nos cursos de formação massificados. Sendo assim, ainda caberia perguntar: Continuaremos formando professores apenas para atender ao modelo hoje instituído pela política educacional atual?

\section{Notas}

1. O grupo de alunos que historicamente têm sido alvo da educação especial tem recebido diversas definiçōes e nomenclaturas. Neste texto, utilizaremos os termos de acordo com as diferentes orientações de cada época. Nesse momento, a Resolução n. 2 de 2001 estabelecia que os alunos com deficiência, transtornos globais do desenvolvimento e superdotados/com altas habilidades compunham o conjunto de alunos com necessidades educacionais especiais.

2. Os dados dos programas apresentados foram levantados em setembro de 2013.

3. Essas informaçôes foram coletadas no portal do MEC, em fevereiro de 2014.

4. Essas informaçōes foram coletadas no portal da Capes/Parfor, em 19 de setembro de 2013.

5. Essas informaçōes foram coletadas no portal do MEC, em 19 de setembro de 2013. 


\section{Referências}

BITTAR, M.; STAPANI RUAS, C.M. Expansão da educação superior no Brasil e a formação dos oligopólios: hegemonia do privado mercantil. EccoS: Revista Cientifica [online], set./dez. 2012. Disponível em: <http:// www.redalyc.org/articulo.oa?id=71524734007>. Acesso em: jan. 2014.

BRASIL. Ministério da Educação. Plano Decenal da Educação. Brasília, DF: MEC, 1993.

BRASIL. Ministério da Educação. Secretaria de Educação Especial. Diretrizes Nacionais para a Educação Especial na Educação Básica. Brasília, DF: MEC/SEESP, 2001.

BUENO, J.G.S. A educação especial nas universidades brasileiras. Brasília, DF: MEC/SEESP, 2002. v. 1.

COSTA, V.A. Formação e teoria critica da Escola de Frankfurt: trabalho, educação, indivíduo com deficiência. Niterói: Eduff, 2005.

GARCIA, R.M.C. Política de educação especial na perspectiva inclusiva e a formação docente no Brasil. Revista Brasileira de Educação, Rio de Janeiro, v. 18, n. 52, p.101-119, mar. 2013.

JESUS, D.M.; BARRETO, M.A.S.C.; GONCALVES, A.F.S. A formação do professor olhada no/pelo GT-15 - Educação Especial da Anped: desvelando pistas. Revista Brasileira de Educação Especial, Marília, v. 17, p. 77-92, ago./set. 2011.

JEZINE, E. O estado da arte da pesquisa em política de educação superior nas regiōes Norte e Nordeste do Brasil. In: ENCONTRO DE PESQUISA EDUCACIONAL DO NORTE E NORDESTE, 21, 2013, Recife. Anais... Recife: UFPE, 2013. Disponível em: <//www.epenn2013.com. br/Encomendados/GT11_TE_Edineide_Jezine_O_Estado_da_Arte_da_ pesquisa_em_Politica_de_Educacao_Superior.pdf $>$. Acesso em: $\mathrm{fev} .2014$.

POSSA, L.B.; NAUJORKS, M.I. Formação de professores em educação especial: os discursos produzidos em textos científicos. In: REUNIẢ̉O ANUAL DA ANPED, 32., 2009, Caxambú. Anais eletrônicos... Caxambú: ANPEd, 2009. Disponível em: <http://32reuniao.anped.org.br/arquivos/ trabalhos/GT15-5759--Int.pdf>. 
A formação de professores para a educação inclusiva e os possíveis impactos...

SAVIANI, D. Formação de professores: aspectos históricos e teóricos do problema no contexto brasileiro. Revista Brasileira de Educação, Rio de Janeiro, v. 14, n. 40, p. 143-155, 2009.

Recebido em fevereiro de 2014.

Aprovado em maio de 2014. 